\title{
ASSOCIATION OF EXCESSIVE MOBILE PHONE USAGE WITH SLEEP QUALITY AND FATIGUE SEVERITY: AN EPIDEMIOLOGIC SURVEY IN SAUDI POPULATION
}

\section{Thamir Al-khlaiwi', Syed Shahid Habib ${ }^{1 \otimes}$}

\begin{abstract}
OBJECTIVE: To determine the effect of mobile phone usage on sleep quality and fatigue severity through standard questionnaires in Saudi Arabia mobile phone users.

METHODS: This cross-sectional study was conducted in Riyadh, Saudi Arabia on 25 I mobile phone users from September 2019 to January 2020. Volunteer mobile phone users aging 15-65 years were selected by nonprobability convenience sampling technique from the Riyadh city community. The subjects were interviewed about the knowledge, attitude and practice of mobile phone use and were assessed through Pittsburg Sleep Quality Index (PSQI) and Fatigue Severity Scale (FSS). Spearman's correlations and Linear regression were applied for statistical analysis through SPSS V.22.
\end{abstract}

RESULTS: Mean age of the participants was $32.43 \pm 12.80$ years, while mobile phone usage was II.7 \pm 4.6 years. Median PSQI score was 6.0 and interquartile range (IQR) was 5. Median FSS score was $3.0(\mathrm{IQR}=3)$. There was a significant increase in PSQI and FSS with the increase daily mobile usage. When participants exceeded one-hour daily usage, PSQI $(<\mathrm{l} h=3.75, \mathrm{I}-2 \mathrm{~h}=5.78,>2 \mathrm{~h}=6.85, \mathrm{p}=$ $0.00 \mathrm{I})$ and FSS $(<\mathrm{I} h=2.25, \mathrm{I}-2 \mathrm{~h}=3.17,>2 \mathrm{~h}=3.6 \mathrm{I}, \mathrm{p}=0.008)$ exceeded acceptable scores. Moreover, placing mobile phone inside bedroom was associated with the increase of PSQI (Near Pillow $=6.93$, Inside Bed=6.16, Outside bed $=5.75, p=0.00 \mathrm{I}$ ) and FSS (Near Pillow $=3.65$, Inside Bed=3.39, Outside Bed $=2.58, p=0.008$ ). Significant correlation was observed between high PSQI and FSS with daily usage $(r=0.213, p=0.001 \& r=0.171, p=0.01$ respectively).

CONCLUSION: Inappropriate and excessive mobile phone usage is associated with poor sleep quality and excessive fatigue in Saudi Arabian population.

KEY WORDS: Cell Phone (MeSH); Sleep disturbance (non-MeSH); Radiation (MeSH); Fatigue (MeSH); Fatigue severity scale (FSS) (non-MeSH); Pittsburg Sleep Quality index (PSQI) (non-MeSH).

THIS ARTICLE MAY BE CITED AS: Al-khlaiwi T, Habib SS. Association of excessive mobile phone usage with sleep quality and fatigue severity: an epidemiologic survey in Saudi population. Khyber Med Univ J 2020;13(2):60-5. https://doi.org/l0.35845/kmuj.2021.20531.

\section{INTRODUCTION}

$\mathrm{F}$ unctionality of mobile phone is exceeding its purpose of making calls and sending SMS. Many social media users are facing great challenges to setup personal limits from using social media. This can be maladaptive behavior as smart phone users want to stay connected roundthe-clock by documenting their personal life via personal account, interacting with friends, following celebrities' stories, etc. Although there are many advantages of having readily accessible internet connections in hand, however; the adversity of carrying mobile phone to the bedrooms has its negative implications. The International Classification of Sleep Disorders (ICSD3) has defined insufficient sleep as consistent deprivations of sleep manner for a period of three months on a daily span, along with, sleepiness complaints
I: Department of Physiology, College of Medicine, King Saud University, Riyadh, Kingdom of Saudi Arabia.

Emailه: sshahid@ksu.edu.sa

Contact \#: +97-01-4671616

Date Submitted: June 30, 2020

Date Revised: May 24, 2021

Date Accepted: May 26,202I

during the daytime.' In 2012, The Centers for Disease Control and Prevention released data about how sleep duration among adults decreased since 1985, and the percentage of adults who are sleeping less than six hours per day increased from $22 \%$ to about $30 \%$. The National Sleep Funding (NSF) in United States recommends at least 8-10 hours of sleep is required for a healthy adolescent.

The research data is quite alarming as smart phones and social media applications have developed rapidly since 2012. Lack of self-discipline on smart phone use has many negative health implications including sleep disorders. A study conducted in 844 participants aged 18-94 years old showed that six out of ten people are carrying on the use of smart phones to bed at the cost of adequate time of sleep. Therefore, effecting sleeping pattern, which was reported by participants as sleep disturbance, daytime fatigue, tiresome and dysfunction due to having less sleep hours. ${ }^{3}$ Another study conducted on adults who were indulging themselves on social media use in-bed showed symptoms like insomnia, sleepiness during the day, mood dysfunction. ${ }^{4}$ Lack of sleep leads in adults to worrisome health morbidities such as likely to suffer from overweight, diabetes mellitus, and premature mortality due to vehicle crash, workplace accidents and cardiovascular disorders. ${ }^{5}$ Adults who did not have adequate sleep duration have adverse job performance. A study that tackled how job performance is affected by lacking sleep showed that employees who do not have enough 
TABLE I: SPEARMAN'S CORRELATIONS BETWEEN PSQI AND FSS WITH MOBILE USE DURING SLEEP, WISH TO QUIT MOBILE USE, METHOD OF USAGE, DAILY USAGE AND MOBILE DEPENDENCY

\begin{tabular}{|c|c|c|c|c|c|c|c|c|c|}
\hline Variables & $\begin{array}{l}\bar{\alpha} \\
\text { ֻ }\end{array}$ & ư & 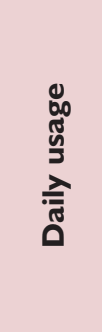 & 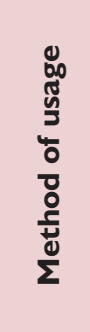 & $\begin{array}{l}\frac{0}{0} \\
\frac{0}{n} \\
00 \\
\frac{0}{2} \\
\frac{0}{3} \\
0 \\
0 \\
\frac{0}{0} \\
\frac{0}{\Sigma}\end{array}$ & $\begin{array}{l}\text { তे } \\
\frac{0}{0} \\
\frac{0}{0} \\
\frac{c}{0} \\
\frac{0}{0} \\
\frac{0}{0} \\
0 \\
\frac{0}{0} \\
\frac{0}{\Sigma}\end{array}$ & 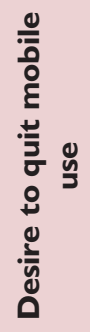 & 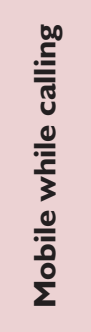 & 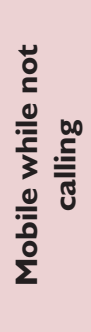 \\
\hline PSQI & 1.000 & $.263^{* *}$ & $.213^{* *}$ & -.053 & -.085 & -.057 & .052 & .017 & .066 \\
\hline FSS & $.263^{* *}$ & 1.000 & $\left..17\right|^{* *}$ & .001 & $-.133^{*}$ & -.061 & $.158^{*}$ & .078 & .018 \\
\hline Daily usage & $.213^{* *}$ & $.17 I^{* *}$ & 1.000 & .017 & $-.238^{* *}$ & $-.234^{* *}$ & .083 & -.053 & -.066 \\
\hline Method of usage & -.053 & .001 & .017 & 1.000 & -.049 & -.016 & .056 & .074 & .030 \\
\hline Mobile during sleep & -.085 & $-.133^{*}$ & $-.238^{* *}$ & -.049 & 1.000 & $.277^{* *}$ & -.012 & $.132^{*}$ & -.048 \\
\hline Mobile dependency & -.057 & -.061 & $-.234^{* *}$ & -.016 & $.277^{* *}$ & 1.000 & -.067 & .013 & .079 \\
\hline Desire to quit mobile use & .052 & $.158^{*}$ & .083 & .056 & -.012 & -.067 & 1.000 & .055 & -.028 \\
\hline Mobile while calling & .017 & .078 & -.053 & .074 & $.132^{*}$ & .013 & .055 & 1.000 & $.208^{* *}$ \\
\hline Mobile while not calling & .066 & .018 & -.066 & .030 & -.048 & .079 & -.028 & $.208^{* *}$ & 1.000 \\
\hline
\end{tabular}

PSQI: Pittsburg sleep quality index. FSS: Fatigue severity scale

sleep are more likely to make mistakes and prone to job related injuries.

A study included about 700 adolescents has shown that the majority of the respondents are using the smartphones excessively before the bedtime and equal number have shown initial signs of insomnia, poor academic achievements, lack of social interaction, and depression. Another study has examined that the participants who are using mobile phones before bedtime are sleeping less than 8 hours a day, which is less than what has been recommended by the NSF. Moreover, those adolescents have complaints about difficulties to enjoy school, tiredness during the day, difficulties to get ready to go to school and difficulty to sleep. ${ }^{8}$ It has been found that night-time duration use of smartphone by teens has great adversity on mental health, as the child will be more emotionally drained.' Many research studies have revealed that adolescents who are using cellphones for long time at nighttime have inadequate sleep duration, weak academic performance, drowsiness and sleepiness during the daylight. ${ }^{10-13}$ However, up to the best of our knowledge there is no study showing relationship between mobile phone usage and sleep disturbance and fatigue using Pittsburg Sleep Quality index (PSQI) and Fatigue severity scale (FSS) in Saudi Arabia to explore the gaps in knowledge between mobile phone usage, sleep and fatigue. Therefore, this study was conducted to determine the association of mobile phone, sleep quality, and fatigue on Saudi Arabia mobile phone users by using PSQI and FSS.

\section{METHODS}

This cross-sectional study was conducted at Department of Physiology, King Saud University Medical City, King Saud University, Riyadh, Kingdom of Saudi Arabia from September 2019 to January 2020. Two hundred and fifty-one volunteer mobile phone users, ranging in age from 15-65 years were selected by non-probability, convenience sampling technique from the Riyadh city community. Mobile phone users with history of known psychiatric disorders, central nervous system disorders, or living near high voltage electricity towers, and malignancy were excluded from the study. Mobile phone users who were regularly smokers were also excluded since smoking acts as a confounder for sleep and fatigue patterns. The study followed the "Declaration of Helsinki" guidelines. It was approved by the "Institutional Review Board, Ethics Committee," College of Medicine Research Centre, King Saud University (E-19-4232).

Detailed clinical history was obtained from the study participants. Knowledge, attitude, and practices were assessed by interview using a pre-designed questionnaire in both Arabic and English languages. One aspect of our study project, addressing smart mobile phone usage and cognitive function impairment in same population has already been published. ${ }^{14}$

We used PSQI to assess sleep quality patterns (PSQI score less than 5 is considered normal). FSS was used to assess fatigue severity (FSS less than 4 is considered normal). The participants were grouped according to the PSQI and FSS severity scales for comparing different variables related to mobile phone usage as explained in the results sections. The total time of the interview was around 15 minutes. All the participants signed a written consent form.

SPSS V. 22 was used for data entry and analysis. ANOVA was used for multiple comparisons. Spearman's correlations were determined between PSQI, FSS and mobile phone usage indices. Linear regression model was created to determine significant predictors of poor sleep quality and fatigue severity.

\section{RESULTS}

Mean age of the participants was $32.43 \pm 12.80$ years, while mobile phone usage was I I.7 \pm 4.6 years. Demographic details were given in our already published article from same project. ${ }^{14}$ The present study shows the relationship of mobile 


\section{TABLE II: LINEAR REGRESSION MODEL WITH PITTSBURG SLEEP QUALITY INDEX SCORES AS DEPENDENT VARIABLE ADJUSTED FOR GENDER AND AGE}

\begin{tabular}{|l|c|c|c|c|}
\hline Model Dependent Variable: PSQI & $\begin{array}{c}\text { Unstandardized Beta } \\
\text { Coefficients }\end{array}$ & $\begin{array}{c}\text { Standardized Beta } \\
\text { Coefficients }\end{array}$ & t & Sig. \\
\hline Daily usage & 1.380 & .227 & $3.45 \mathrm{I}$ & $.00 \mathrm{I}$ \\
\hline Method of usage & -0.132 & -.036 & -.584 & .559 \\
\hline Mobile dependency & -0.124 & -.027 & -.409 & .683 \\
\hline Desire to quit mobile use & 0.125 & .027 & .439 & $.66 \mathrm{I}$ \\
\hline Mobile during sleep & -0.066 & -.013 & -.188 & $.85 \mathrm{I}$ \\
\hline
\end{tabular}

phone usage with sleep patterns and fatigue severity. We observed a significant increase in PSQI and FSS with the increase daily mobile usage.

Median PSQI score was 6.0 and interquartile range (IQR) was 5. Median FSS score was $3.0(\mathrm{IQR}=3)$.

More than $54 \%$ of the participants place their mobile phone near their pillow while sleeping (obtained from our previous study mentioned earlier).

Figure I showed PSQI scores and FSS in mobile phone users according to daily usage. PSQI scores increased progressively significantly when participant's daily mobile phone usage increased. When participants exceeded one-hour daily usage, PSQI exceeded normal score of 5 (cut off PSQI score is 5 ), while when it was less than one hour, the PSQI score was less than 5 which is normal $(<\mathrm{Ih}=3.75, \quad \mathrm{I}-2 \mathrm{~h}=5.78$, $>2 \mathrm{~h}=6.85$ with $\mathrm{p}=0.00 \mathrm{I})$. When mobile daily usage increased, fatigue severity score increased progressively $(<\mathrm{lh}=2.25, \mathrm{I}-2 \mathrm{~h}=3.17,>2 \mathrm{~h}=3.6 \mathrm{I}$ with $\mathrm{p}=0.008$ ).

Figure 2 showed the PSQI scores and FSS according to the placement of the mobile phone while sleeping; The PSQI score decreased $(N P=6.93, I B=6.16$, $O B=5.75$ with $p=0.001)$ and FSS decreased $(N P=3.65, I B=3.39$, $\mathrm{OB}=2.58$ with $\mathrm{p}=0.008$ ) when participants placed their mobile away from their body. Even though the effect of the placement of the mobile phone during sleep did not bring the scores to the normal level (PSQI less than 5, FSS less than 4), but at least there was a significant difference between the groups.

Spearman's correlations were determined between PSQI and FSS with mobile use during sleep, wish to quit mobile use, method of usage, daily usage and mobile dependency (table I). Significant correlation was observed between high PSQI and FSS with daily usage $(r=.213, p=0.001$ and $r=.171$, $p=0.0$ I respectively). Also, desire to quit mobile use correlated significantly with high FSS. Afterwards, age and gender adjusted linear regression models were created with PSQI scores and FSS as dependent variables while, mobile use during sleep, wish to quit mobile use, method of usage, daily usage and mobile dependency as predictors (table II \& III). ANOVA from both models gave significant values. The significant predictor for PSQI was daily mobile phone usage while the predictors for FSS were daily mobile phone usage and desire to quit mobile use.

\section{DISCUSSION}

This study investigated the association between the mobile phone usage and sleep disturbance and fatigue severity in Saudi Arabia. In this study, it was

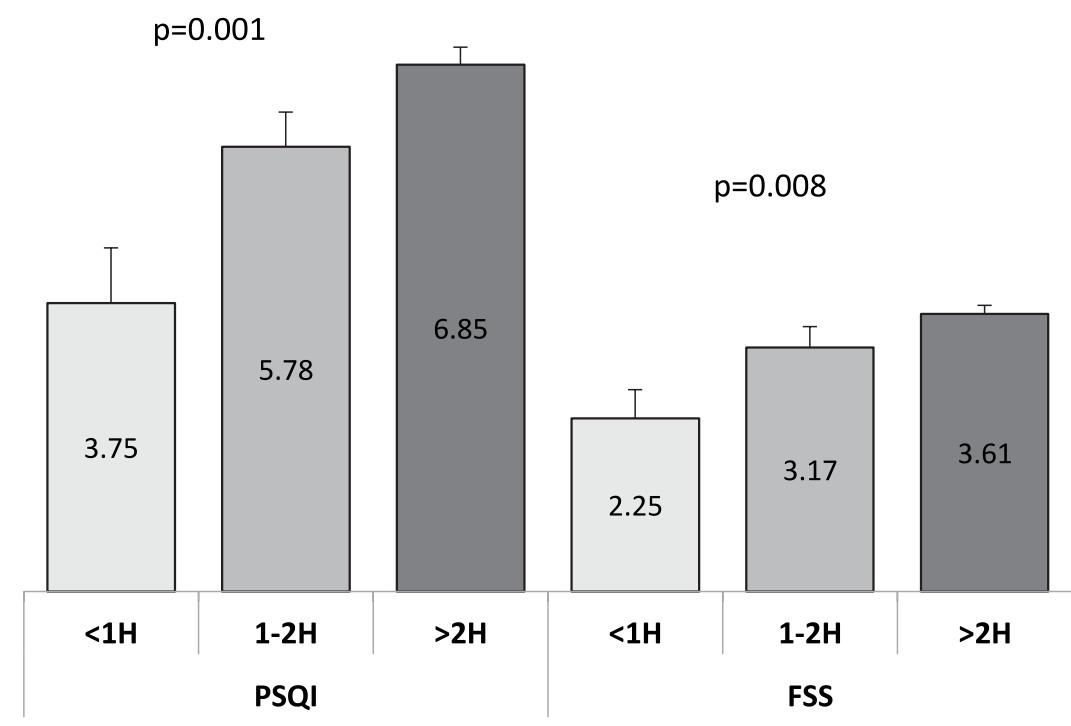

Figure I: Pittsburg Sleep Quality Index (PSQI) scores and Fatigue Severity Scale (FSS) in mobile phone users according to daily usage in hours 


\section{TABLE III: LINEAR REGRESSION MODEL WITH PITTSBURG SLEEP QUALITY INDEX SCORES AS DEPENDENT VARIABLE ADJUSTED FOR GENDER AND AGE}

\begin{tabular}{|l|c|c|c|c|}
\hline Model Dependent Variable: FSS & $\begin{array}{c}\text { Unstandardized Beta } \\
\text { Coefficients }\end{array}$ & $\begin{array}{c}\text { Standardized Coefficients } \\
\text { Beta }\end{array}$ & t & Sig. \\
\hline Daily usage & 0.537 & .175 & 2.675 & .008 \\
\hline Method of usage & 0.001 & .001 & .010 & .992 \\
\hline Mobile dependency & -0.007 & -.003 & -.046 & .963 \\
\hline Desire to quit mobile use & 0.364 & .157 & 2.545 & .012 \\
\hline Mobile during sleep & -0.306 & -.116 & -1.741 & .083 \\
\hline
\end{tabular}

FSS: Fatigue severity scale

the mobile phone usage and sleep disturbance and fatigue severity in Saudi Arabia. It was observed that more than $61 \%$ of the participants have been using the mobile phone for more than 10 years which is most striking.

This is a fact in Saudi Arabia that even kids in grades five and six have mobile phones which became very difficult for us to find participants that do not use the mobile for less than one year. More than $80 \%$ of the participants use the mobile phone for more than two hours daily which became a well-established habit in the society. In addition, participants use handheld mode for calling (>61\%) which is consistent with the lack of the awareness of putting the mobile phone away from your body ${ }^{14}$. In addition, more than 54\% of the participants put their mobile phone near their heads while sleeping which can be associated with the sleep disturbance

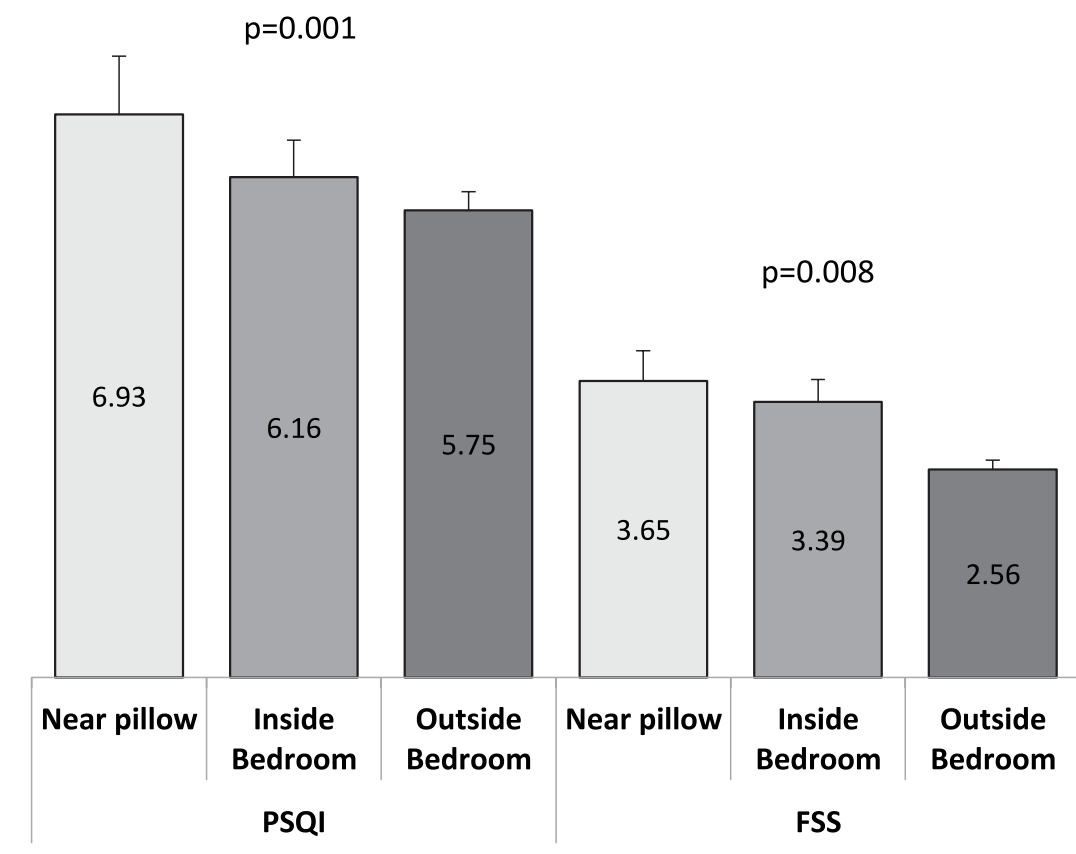

Figure 2: Pittsburg Sleep Quality Index (PSQI) scores and Fatigue Severity Scale (FSS) in all participants according to mobile phone location while sleeping

and eventually affecting the fatigability of the participants.

In this study, it was identified that sleep disturbance increased with the increase of mobile phone usage. Also, fatigue severity increased with the daily increase of mobile phone which could be due to direct effect of the radiation omitted by the mobile phone on the participants or due to the sleep disturbance which increases fatigability eventualy. Our results are consistent with the results of other studies that concluded the relationship of inappropriate mobile phone usage and sleep disturbance. ${ }^{3,22,23}$ In addition, our results indicate that even small changes in the attitude and the practices of mobile phone usage can affect the sleep quality and fatigability. According to our results, one should not exceed onehour of daily usage of mobile phone. In addition, in our report, the co-existence

KMUJ 202I, Vol. I 3 No.2 of sleep disturbance and increase fatigue severity was significantly related and associated with the position of mobile placement during sleeping hours. This could be due to the effect of the radiation of the devise or due to the distraction of the mobile phone of participants from healthy sleep pattern by keeping them awake. Tattamanti G, et al, found that sleep disturbance was not due RF-EMFR but due to highest call-time category. ${ }^{24}$

\section{STUDY STRENGTHS AND LIMITATIONS}

To the best of our knowledge this is the first report on the effect of excessive use of mobile phone on sleep patterns and fatigue severity in Saudi Arabia. Possible limitations could be its crosssectional design and small number of subjects. Finding participants with mobile phone usage of less than $60 \mathrm{~min}$ daily was a challenge and it shows that it has become a common habit of our society. More researches at larger scale are needed to explore the effects of mobile phone usage on sleep and fatigue and also to determine preventive measures for its side effects.

\section{CONCLUSION}

The present study reveals that excessive use of mobile phone is associated with sleep disturbance and increase fatigue severity assessed by PSQI and FSS. Arguably enough, although there are many factors that are contributing to sleep disorders, however; sleep disorder that is caused by excessive smartphone use is undeniably alarming and affecting both adults and children worldwide which raise global health concerns.

Mobile phone becomes nowadays one of the major pillars of modern life and it would be so difficult to quit using it. 
Mobile phone usage should be restricted highly important works and organized. Health care providers and ministry of education should educate the public sector about the hazardous effects of inappropriate usage.

\section{REFERENCES}

I. Chapman, DP, Croft JB, Liu Y, Perry GS, Presley-Cantrell LR, Ford ES. Excess Frequent Insufficient Sleep in American Indians/Alaska Natives. J Environ Public Health 2013;2013: 259645. https://doi.org/10.1155/ 2013/259645.

2. Matsumoto T, Chin K. Prevalence of sleep disturbances: Sleep disordered breathing, short sleep duration, and non-restorative sleep. Respir Investig 2019;57(3):227-37. https://doi.org/ I0.1016/j.resinv.2019.01.008.

3. Exelmans L, den Bulck JV. Bedtime mobile phone use and sleep in adults Soc Sci Med 2016;148:93-10I. https://doi.org/10.1016/j.socscimed. 2015.11 .037$.

4. Bhat S, Pinto-Zipp G, Upadhyay H, Polos PG. To sleep, perchance to tweet": in-bed electronic social media use and its associations with insomnia, daytime sleepiness, mood, and sleep duration in adults. Sleep Health 2018;4(2):166-73. https:// doi.org/10.1016/j.sleh.2017.12.004.

5. Chattu VK, Manzar M, Kumary S, Burman D, Spence DW, PandiPerumal SR. The global problem of insufficient sleep and its serious public health implications. Healthcare (Basal) 20I9;7(I):I. https://doi.org/ 10.3390/healthcare701000I.

6. Ferguson SA, Appleton SL, Reynolds AC, Gill TK, Taylor AW, McEvoy RD, et al. Making errors at work due to sleepiness or sleep problems is not confined to non-standard work hours: results of the 2016 Sleep Health Foundation national survey. Chronobiol Int 2019;36(6):758-69. https://doi.org// 0.1080/07420528. 2019.157.

7. Dewi, RK, Efendi F, Has EMM, Gunawan J. Adolescents' smartphone use at night, sleep disturbance and depressive symptoms. Int J Adolesc
Med Health 20I8;33(2):20I80095 https://doi.org//0.15 I5/ijamh2018-0095.

8. Garmy P, Ward TM. Sleep habits and nighttime texting among adolescents. J Sch Nurs 2018;34(2): I 2 I-7. https://doi.org// 0.1 I 77// 0598405 17704964.

9. Woods HC, Scott H. Sleepyteens: Social media use in adolescence is associated with poor sleep quality, anxiety, depression, and low selfesteem. J Adolesc 2016;51:41-9. https://doi.org//0.1016/ j.adolescence.2016.05.008.

10. Grover K, Pecor K, Malkowski M, Kang L, Machado S, Lulla R, Heisey $D$, Ming $X$. Effects of instant messaging on school performance in adolescents. J Child Neurol 2016 Jun;3I(7):850-7. https://doi.org/ 10.1 I77/08830738I5624758.

II. Short MA, Gradisar M, Lack LC, Wright HR. The impact of sleep on adolescent depressed mood, alertness and academic performance. J Adolesc 2013;36(6): I025-33. https://doi.org/ 10.1016/j.adolescence.2013.08.007.

12. Mohammadbeigi A, Absari R, Valizadeh F, Saadati M, Sharifimoghadam S, Ahmadi A, et al. Sleep quality in medical students; the impact of over-use of mobile cellphone and social networks. J Res Health Sci 20 I 6; I 6(I):46-50.

13. Hale L, Guan S. Screen time and sleep among school aged children and adolescents: a systematic literature review. Sleep Med Rev 2015;21:508. https://doi.org/10.1016/j.smrv. 20।4.07.007.

14. Al-Khlaiwi T, Meo SA. Association of mobile phone radiation with fatigue, headache, dizziness, tension and sleep disturbance in Saudi population. Saudi Med J 2004;25(6), 7326.

15. Xie YJ, Cheung DSK, Loke AY, Nogueira BL, Liu KM, Leung AY, et al. Relationships between television viewing, computer and mobile phone usage and sleep quality in a chinese population: a communitybased cross-sectional study. J Med Internet Res 2020;22(7):el8095. https://doi.org//0.2196/18095.
16. Hong W, Liu R, Ding Y, Sheng X, Zhen R. Mobile phone addiction and cognitive failures in daily life: the mediating roles of sleep duration and quality and the moderating role of trait self-regulation. Addict Behav 2020;107:106383. https://doi.org/ 10.1016/j.addbeh.2020.106383.

17. Liu X, Luo Y, Liu ZZ, Yang Y, Liu J, Jia CX. Prolonged mobile phone use is associated with poor academic performance in adolescents. Cyberpsychol Behav Soc Netw 2020;23(5):303-II. https://doi.org/ 10.1089/cyber.2019.0591.

18. Meo SA, Al-Drees, AM. Mobile phone related hazards and subjective hearing and vision symptoms in the Saudi population. Int J Occup Med Environ Health 2005; I8(I):53-7.

19. Meo SA, Alsubaie Y, Almubarak Z, Almutawa $\mathrm{H}$, AlQasem $\mathrm{Y}$, Hasanato RM. Association of exposure to radio-frequency electromagnetic field radiation (RF-EMFR) generated by mobile phone base stations with glycated hemoglobin (HbAlc) and risk of type 2 diabetes mellitus. Int J Environ Res Public Health 2015; 12 (I I): I45 I9-28. https://doi.org/ 10.3390/ijerph I 2 I | 4519 .

20. Chetty-Mhlanga S, Fuhrimann S, Eeftens M, Basera W, Hartinger S, Dalvie MA, Röösli M. Different aspects of electronic media use, symptoms and neurocognitive outcomes of children and adolescents in the rural Western Cape region of South Africa. Environ Res 2020; 184 : I093 | 5.https://doi.org/10.1016/ j.envres. 2020.1093I5.

21. Al-khlaiwi TM, Habib SS, Meo SA, Alqhtani MS, Ogailan AA. The association of smart mobile phone usage with cognitive function impairment in Saudi adult population. Pak J Med Sci 2020;36(7): 1628-33. https://doi.org//0.12669/ pjms.36.7.2826.

22. Deniz O, Kaplan S, Selçuk M, Terzi $M$, Altun G, Yurt K, et al. Effects of short and long term electromagnetic fields exposure on the human hippocampus. J Microsc Ultrastruct 2019;5(4)-191-7. https://doi.org/ I0.1016/j.jmau.2017.07.00I. 
23. Saikhedkar N, Bhatnagar M, Jain A, Sukhwal P, Sharma C, Jaiswal N. Effects of mobile phone radiation (900 $\mathrm{MHz}$ radiofrequency) on structure and functions of rat brain. Neurol Res 2014; 36(12):1072-9.
https://doi.org/I0.1 I79/1743/328 |4Y.0000000392.

24. Tettamanti G, Auvinen A, Åkerstedt T, Kojo K, Ahlbom A, Heinävaara S, et al. Long-term effect of mobile phone use on sleep quality: results from the cohort study of mobile phone use and health (COSMOS). Environ Int 2020;|40:105687. https://doi.org/10.1016/j.envint. 2020.105687.

\section{AUTHOR'S CONTRIBUTION}

Following authors have made substantial contributions to the manuscript as under:

TA: Conception and study design, acquisition of data, drafting the manuscript, critical review, approval of final version to be published

SSH: Acquisition, analysis and interpretation of data, drafting the manuscript, approval of final version to be published

Authors agree to be accountable for all aspects of the work in ensuring that questions related to the accuracy or integrity of any part of the work are appropriately investigated and resolved.

CONFLICT OF INTEREST
Authors declared no conflict of interest
GRANT SUPPORT AND FINANCIAL DISCLOSURE
Work on this study was supported by Deanship of Scientific Research
(Grant Number: RGP-1438-048) King Saud University, Riyadh, Saudi Arabia

\section{DATA SHARING STATEMENT}

The data that support the findings of this study are available from the corresponding author upon reasonable request.

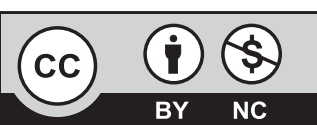

BY NC
This is an Open Access article distributed under the terms of the Creative Commons Attribution-Non Commercial 2.0 Generic License.

KMUJ web address: www.kmuj.kmu.edu.pk

Email address: kmuj@kmu.edu.pk 